\title{
ESCOLAS PÚBLICAS DO MUNICÍPIO DE CURITIBA: AS NOVAS TECNOLOGIAS NAS ESCOLAS DE TEMPO INTEGRAL
}

\author{
ESCUELAS PÚBLICAS DE LA CIUDAD DE CURITIBA: NUEVAS \\ TECNOLOGÍAS EN ESCUELAS DE TIEMPO COMPLETO
}

\section{PUBLIC SCHOOLS OF CURITIBA CITY: NEW TECHNOLOGIES IN FULL TIME SCHOOLS}

\author{
Rozane de Fátima Zaionz da ROCHA ${ }^{1}$ \\ Herivelto MOREIRA ${ }^{2}$
}

RESUMO: O artigo teve como objetivo identificar a contribuição da formação inicial para a efetivação de práticas pedagógicas inovadoras no contexto da escola de tempo integral. O referencial teórico baseou-se na formação inicial dos professores e no uso das novas tecnologias com os alunos das escolas de tempo integral. Este estudo é uma pesquisa de método qualitativo. A escolha da abordagem qualitativa para esse estudo se deu em virtude de ser uma abordagem oportuna para investigar situações cotidianas em um novo contexto. A técnica de coleta de dados foi a entrevista individual semiestruturada (conversação gravada e depois transcrita, tendo apenas um roteiro inicial com perguntas abertas) realizada com quinze professores de diferentes escolas localizadas em oito regionais no município de Curitiba. Da análise dos dados emergiram duas categorias que tratam da formação inicial dos professores e também as implicações das TICs nas escolas de tempo integral. Os dados mostram que há divergência entre os professores no que diz respeito ao uso das TICs nas escolas de tempo integral, ou seja, os professores que tiveram formação inicial no uso das TICs em sala de aula consideram que os alunos matriculados nas escolas de tempo integral têm mais acesso às TICs, como também, demonstram apresentar melhor oralidade e argumentação em relação aos alunos que ficam em tempo regular. Os professores que não tiveram formação incial para uso das TICs consideram que a ampliação da jornada diária não implica em maior acesso às TICs e melhor desempenho no processo ensino e aprendizagem.

PALAVRAS-CHAVE: Tecnologias da Informação e Comunicação. Formação de professores. Educação em tempo integral.

RESUMEN: El objetivo del trabajo fue identificar la contribución de la formación inicial para la realización de prácticas de enseñanza innovadoras en el contexto de la escuela a tiempo completo. El marco teórico se basa en la formación inicial de los maestros y el uso de las nuevas tecnologías con los alumnos de las escuelas de tiempo

\footnotetext{
${ }^{1}$ Doutoranda do Programa de Pós-Graduação em Tecnologia da Universidade Tecnológica Federal do Paraná. Email: rozanerocha@hotmail.com

${ }^{2}$ Professor e Pesquisador do Programa de Pós-Graduação em Tecnologia da Universidade Tecnológica Federal do Paraná. E-mail: herivelto.moreira51@gmail.com
} 
completo. Este estudio es un método de investigación cualitativa. La elección de un enfoque cualitativo de este estudio fue debido a ser un enfoque puntual para investigar situaciones cotidianas en un nuevo contexto. La técnica de recolección de datos fue la semi-estructuradas entrevistas individuales (conversación grabada y luego transcrita, con solamente un guión inicial con preguntas abiertas) que tenga con quince profesores de diferentes escuelas en ocho regional en Curitiba. Análisis de los datos surgieron dos categorías que se ocupan de la formación inicial de los maestros y también las implicaciones de las TIC en las escuelas de todo el día. Los datos muestran que existe un desacuerdo entre los profesores con respecto al uso de las TIC en escuelas de jornada completa, o maestros que tenían una formación inicial en el uso de las TIC en el aula, consideran que los estudiantes matriculados en escuelas diurnas plena tener más acceso a las TIC, sino que también demuestran una mejor presentación oral y en relación con los estudiantes que están en el tiempo regular. Los maestros que no tenían formación inicial para el uso de las TIC consideran que la ampliación de la jornada laboral no implica un mayor acceso a las TIC y un mejor rendimiento en la enseñanza y el aprendizaje.

PALABRAS CLAVE: Tecnologías de la Información y Comunicación. Formación de profesores. educación a tiempo completo.

ABSTRACT: The objective of this article was to identify the contribution of the initial training for the realization of innovative teaching practices in the context of school fulltime. The theoretical framework of this study was based on the initial training of teachers and the use of new technologies with students from schools that offer extension of the residence time / day of the student. This study is a qualitative research method. The choice of a qualitative approach to this study, which is part of the doctoral thesis, was due to be a timely approach to investigate everyday situations in a new context. The data collection technique was the semi-structured individual interviews (recorded conversation and then transcribed, with only an initial script with open questions) held with fifteen teachers from different schools in eight regional in Curitiba. Data analysis emerged among others, the categories dealing with the initial training of teachers and also the implications of ICT in all-day schools. The data show that there is disagreement among teachers regarding the use of ICT in all-day schools, or teachers who had initial training in the use of ICT in the classroom, consider that students enrolled in day schools full have more access to ICTs, but also demonstrate better present oral argument and in relation to students who are in regular time. Teachers who had no initial training for use of ICTs consider that the expansion of the workday does not imply greater access to ICTs and better performance in the teaching and learning.

KEYWORDS: Information and Communication Technology. Teacher training. Fulltime education. 


\section{Introdução}

A atual sociedade exige dos indivíduos novos conhecimentos, dentre eles, o domínio da linguagem digital. Considerando que a escola é elemento na sociedade, a apropriação de diferentes conhecimentos e linguagens também se faz presente nesse ambiente, mais propriamente na escola de tempo integral ${ }^{3}$, a qual vêm apresentando crescente evolução no número de matrículas ano a ano (MEC, INEP, 2014). Conforme o Censo da Educação Básica, realizado no ano de 2013 no Brasil, a educação em tempo integral na rede pública nos anos de 2012 e 2013 teve crescimento de 46,5\%.

Considerando que o aluno fica de sete a nove horas no ambiente escolar, essa ampliação do tempo de permanência necessita ser minuciosamente planejada a fím de atender às expectativas da atual sociedade.

Conforme Takahashi (2000, p.7), as escolas necessitam ter mais infraestrutura moderna de comunicação e precisam ter nos professores a competência para transformar a informação em conhecimento, efetivando dessa maneira a sua função social.

Rivoltella (2012) e Brandão (et.al. 2004) defendem que o professor não se sente à vontade para utilizar as mídias digitais em suas aulas devido ao difícil acesso e também ao pouco ou nenhum domínio que possui das ferramentas para fins pedagógicos.

Na concepção de Takahashi (2000, p. 7), a educação precisa prover condições para que os indivíduos apresentem competências e habilidades para interagir e (re)inventar na sociedade em que vivem. Independente da classe social, necessitam ser indivíduos com possibilidades de participar ativamente das decisões e mudanças.

Assim, o objetivo do artigo foi identificar qual a contribuição da formação inicial para a efetivação de práticas pedagógicas inovadoras no contexto da escola de tempo integral.

\section{Metodologia e procedimento}

O estudo foi desenvolvido a partir de uma abordagem qualitativa, oportuna para investigar situações cotidianas em um novo contexto (FLICK, 2009, p.21). A

${ }^{3}$ [...] "considerado como a jornada diária de 7 horas ou mais em que o aluno, durante todo o período letivo, permanece na escola ou em atividades escolares [...]” (MEC, INEP, 2014, p. 18). 
técnica de coleta de dados foi a entrevista individual semiestruturada realizada com quinze professores de oito escolas de tempo integral na rede pública municipal de Curitiba - PR, distribuídas em oito regionais periféricas do município.

O protocolo de entrevista inicial foi elaborado a partir da revisão da literatura e de experiência na docência da pesquisadora, e contemplou vinte e duas perguntas divididas em quatro blocos: O bloco "A" abordou o uso das tecnologias na escola; o bloco "B", a disponibilização das ferramentas, ou seja, quais e quantas ferramentas os professores e alunos tem disponíveis para trabalharem em sala de aula; o bloco "C" contemplou a formação dos professores e o bloco " $\mathrm{D}$ " tratou das práticas docentes. Para testar o entendimento do teor das perguntas por parte dos participantes foram realizadas três entrevistas-piloto.

Em relação ao número de participantes, este não foi definido a priori, pois segundo Bogdan e Biklen (1994, p. 96) "os investigadores qualitativos aferem a altura em que terminaram o estudo quando atingem aquilo que se designam por saturação dos dados $[. .$.$] a partir do qual a aquisição se torna redundante”.$

A amostra final constituiu-se de 15 professores com média de idade de 35 anos. Considerando os níveis de estágio na docência, quatro professores estão no estágio inicial da carreira ( 0 a 5 anos de magistério); cinco professores no estágio intermediário (6 a 12 anos de magistério), e seis em estágio avançado (13 anos ou mais de magistério) (MOREIRA, 2005, p. 214). Em relação à carga horária de trabalho, apenas cinco professores trabalham 20 horas/semanais e 10 trabalham 40 horas/semanais.

Dos quinze professores participantes das entrevistas, sete deles ministram aulas em turmas regulares mistas, ou seja, turmas que contemplam alunos que ficam quatro, e outros alunos que ficam nove horas na escola; e oito professores atuam em oficinas de contraturno e também são corregentes das turmas regulares mistas.

A análise dos dados constituiu-se de exploração das transcrições através da leitura e codificação dos dados que ocorreu com auxílio de software. Após, realizou-se a unificação dos códigos que geraram as categorias preliminares. A conexão das categorias preliminares definiu as categorias finais. A validação dos resultados foi garantida pela triangulação de diferentes fontes de informação, conferência por parte dos entrevistados e revisão do orientador acadêmico. 


\section{Formação de professores: o uso das novas tecnologias com os alunos}

A escola tem por função oferecer a melhor formação integral possível, e isso inclui também a formação para o trabalho. Considerando que vivemos na sociedade da informação e comunicação, os professores necessitam de formação não somente para o manuseio das tecnologias, mas também para associar essas tecnologias e as diferentes linguagens aos conteúdos programáticos, assim como esclarecer sobre sua (in)utilidade no dia a dia e a relação com o consumismo imposto pelo capitalismo. Essas competências e habilidades desafiam a formação docente em relação às novas linguagens, dentre elas a televisiva, a informática e as linguagens de natureza de hipertextos.

Segundo Nóvoa (2001) o professor necessita de novas competências para atuar na sociedade do século XXI. Para o autor, o docente não é mais um mero transmissor de conhecimentos como ocorria em séculos anteriores. O professor é um organizador de aprendizagens via os novos meios informáticos e as novas realidades virtuais. Além de organizador, cabe ao professor a competência de conhecer e (re)elaborar o conhecimento de maneira a compartilhar com os diferentes alunos que compõem o grupo.

As crianças e os jovens estão em constante contato com a informação através de diferentes meios, o que reforça a necessidade de adaptação do professor a essa nova realidade que se apresenta explícita na geração de alunos que frequentam as instituições escolares. De acordo com Freire Filho e Lemos (2008, p. 13), “os indivíduos nascidos depois de meados do ano de 1980, utilizam microcomputadores, internet e telefones celulares para as mais diversas finalidades", essa realidade digital é inerente às pessoas que nasceram depois desse ano. Utilizar as mais diversas mídias para entretenimento, informação, aprendizagem, comunicação, consumo, é algo normal, faz parte da identidade social desses indivíduos.

Essa geração nasceu tendo acesso às tecnologias e por isso a facilidade com que manipulam as mais variadas ferramentas tecnológicas, diferente das gerações anteriores à década de 1980 que necessitaram aprender e se aperfeiçoar no uso desses materiais.

Freire Filho e Lemos (2008), defendem que os professores precisam receber a formação necessária e apropriada para o momento sócio histórico em que vivem. No 
entanto, a formação do profissional que trabalha na docência, além dos conteúdos, deve proporcionar condições de estabelecer vínculos entre tais conteúdos e os melhores instrumentos para se alcançar a aprendizagem dos alunos. Dentre esses instrumentos estão as novas tecnologias, que precisam ser exploradas nos cursos que formam o formador.

Nessa área de discussão, Andrade (2003, p. 58) entende que o uso das tecnologias na educação possibilita o acesso "mais rápido e atualizado das informações", também permite maior inter-relação entre os indivíduos, o que pode contribuir para a construção de novos conhecimentos e novas características para a escola, que segundo o autor, é "responsável pela formação básica dos cidadãos" (ibidem). Isto implica na valorização dos conhecimentos prévios dos indivíduos, do contexto em que vivem, da integração entre as diferentes áreas do conhecimento e da interação social.

O professor somente terá condições de discutir as vantagens e desvantagens das tecnologias na educação se tiver pleno domínio de seu uso no cotidiano escolar. Com esse conhecimento tecnológico direcionado ao uso pedagógico poderá então decidir se as "novas tecnologias contribuem para o desenvolvimento das capacidades cognitivas e comportamentais" (idem) e, dessa maneira, colaborar para a formação da cidadania.

Para Andrade (2003, p. 65), há que se revisar as "formas educacionais em consequência da formação dos educadores", e na visão do autor essa revisão inclui o conhecimento técnico pedagógico das potencialidades do uso das tecnologias em sala de aula e como essas tecnologias podem ser conectadas com uma prática entendida como inovadora.

A prática educativa inovadora, para Andrade (2003, p. 67), refere-se a conhecer e utilizar as potencialidades das ferramentas tecnológicas na educação relacionando-as com os fundamentos pedagógicos. O professor, na concepção do autor, sabe e utiliza o computador, no entanto, ainda não domina essa ferramenta associada ao uso pedagógico.

Para que o professor esteja preparado para discutir e mediar processos de ensino e aprendizagem utilizando as novas tecnologias em sala de aula, precisa de preparação. Porém, no Brasil, apesar das crescentes discussões, "as políticas públicas de formação de professores são quase ausentes na discussão curricular da mídia-educação" (FANTIN, 2012a, p. 76). 
Os Parâmetros Curriculares Nacional (BRASIL, 1997, p. 25) mencionam a necessidade de desenvolver no aluno a capacidade de trabalhar com as tecnologias a fim de atender aos novos desafios da sociedade, haja vista que a tecnologia se faz presente em todos os espaços. Assim, os PCN (1997, p. 67) defendem que “é indiscutível a necessidade crescente do uso de computadores pelos alunos como instrumento de aprendizagem escolar"; cabe à instituição de ensino, em parceria com outras instituições sociais, se instrumentalizar e se preparar para as demandas sociais.

O Parecer 09/2001 norteia os encaminhamentos para a formação de professores com algumas características que se apresentam como imprescindíveis, como por exemplo, "assumir e saber lidar com a diversidade existente entre os alunos; incentivar atividades de enriquecimento cultural; desenvolver práticas investigativas; elaborar e executar projetos para desenvolver conteúdos curriculares; utilizar novas metodologias, estratégias e materiais de apoio" (CNE/CP 9/2001.MINISTÉRIO DA EDUCAÇÃO, 2001, p. 4). Contudo, ainda pode ser observada a falta de obrigatoriedade para disciplinas que qualifiquem os professores em relação ao uso das mídias de maneira crítica e reflexiva na educação.

O uso de TICs por professores já ficou comprovado em pesquisas (ETEOKLEOUS, 2007; PURSELL et al., 2013). No entanto, esse uso se faz de maneira pessoal para acesso às redes sociais, pesquisas, contato com outros professores, ou até mesmo com os próprios alunos, porém, a utilização em sala de aula integrado com o conteúdo é baixa, é pouco usado como ferramenta para a inovação das aulas e produção de novos conhecimentos.

Eteokleous (2007, p. 672) entende que a integração das TICs em sala de aula deve superar os limites das ferramentas utilizadas pelos professores apenas como editores de textos, planilhas, projetores de vídeo. Para a autora, há que se integrar o currículo a essas ferramentas. Para isso, a autora apresenta alguns pontos importantes, dentre eles a qualificação do docente, a compreensão da metodologia de maneira a integrar ferramenta e currículo, assim como a utilização de softwares e hardwares suficientes ao número de alunos. $\mathrm{O}$ planejamento adequado das aulas, $\mathrm{o}$ acompanhamento técnico pedagógico e a avaliação constante dos professores, são fatores que contribuem para o uso das TICs em sala de aula (ibidem).

Em relação ao professor propriamente dito, Eteokleous (2007, p. 672) argumenta que os profissionais que são adeptos das práticas inovadoras, percebem o sujeito ativo no processo de ensino-aprendizagem, e procuram manter contatos 
constantes com seus pares, apresentam maior facilidade no uso das TICs em sala de aula. A autora relata ainda que, em pesquisa realizada com professores, constatou-se que os fatores que influenciam a integração dos computadores em sala de aula podem ser divididos em três categorias: profissional, defendido pela autora como sendo a falta de conhecimento e habilidades dos professores; organizacional, falta de estrutura física e excesso de conteúdos curriculares a ser vencidos no ano letivo, e também fatores atitudinais, relacionados ao ceticismo dos professores em relação às TICs, situação que também foi confirmada em pesquisa realizada pela UNESCO (2004).

Para que o professor possa usar as TICs com eficiência, a formação inicial recebida por esse docente é imprescindível. Para Gatti (2003, p. 192), o professor que cursa licenciatura em Pedagogia se capacita metodologicamente para atuar na educação, principalmente no ensino fundamental, ficando frágil a formação em relação ao conteúdo que trabalhará com os alunos. Outra situação é a formação obtida nas licenciaturas em áreas como Geografia, História, Matemática, Língua Portuguesa, que enfatizam o conteúdo e fragilizam a metodologia.

Conseguir as mudanças desejadas nas práticas pedagógicas em sala de aula é algo mais complexo, pois não se alcança apenas com o desenvolvimento profissional em serviço. Necessita sim, formação na base, ou seja, nos cursos de formação docente.

$\mathrm{Na}$ educação em tempo integral, a formação profissional é ainda mais necessária, pois o professor trabalhará com alunos que estão nove horas na escola. Gadotti (2009, p. 104) considera que:

É importante acrescentar ainda que a adoção e implantação de um projeto de educação integral não devem sobrecarregar os professores. Não se trata de aumentar o seu tempo de trabalho, mas, muito mais, de utilizar esse tempo de forma diferenciada. Por isso, não se pode implementar um projeto de educação integral sem uma sólida formação de todos os segmentos da escola, particularmente dos professores [...].

O professor atuante em escolas de tempo integral, contribuirá para o desenvolvimento e a formação da identidade desses alunos, já que esses passarão a maior parte de sua infância e adolescência no interior da instituição escolar. Contudo, essa contribuição poderá ou não se efetivar nas escolas de tempo integral, dependerá da formação recebida. 


\section{Formação inicial de professores: avanços no tempo e no espaço e as contribuições para o uso das novas tecnologias em sala de aula}

Essa categoria trata da opinião dos participantes do estudo sobre a contribuição da formação inicial para o uso das TICs com alunos nas escolas de tempo integral.

Quando perguntado aos participantes do estudo qual foi a contribuição da formação inicial para o uso das TICs em sala de aula, identificou-se uma variação significativa de respostas em função da época em que se deu esta formação, tempo de docência e tipo de formação. Essa variação de respostas permitiu a formação de três grupos, conforme pode ser observado no Quadro 1:

Quadro 1 - Agrupamento dos participantes do estudo de acordo com o período da conclusão da graduação

\begin{tabular}{|c|c|c|c|c|}
\hline Grupo & Participantes & Graduação & $\begin{array}{l}\text { Período de } \\
\text { conclusão } \\
\text { da graduação }\end{array}$ & $\begin{array}{c}\text { Tempo na } \\
\text { Docência (anos) }\end{array}$ \\
\hline 1 & $\begin{array}{c}\text { P5 } \\
\text { P11 } \\
\text { P13 }\end{array}$ & $\begin{array}{l}\text { Pedagogia } \\
\text { Pedagogia } \\
\text { Pedagogia }\end{array}$ & 1984 a 1999 & $\begin{array}{l}21 \text { anos } \\
20 \text { anos } \\
27 \text { anos }\end{array}$ \\
\hline 2 & $\begin{array}{l}\text { P1 } \\
\text { P2 } \\
\text { P3 } \\
\text { P4 } \\
\text { P6 } \\
\text { P7 } \\
\text { P12 } \\
\text { P15 }\end{array}$ & $\begin{array}{l}\text { Letras } \\
\text { Pedagogia } \\
\text { Pedagogia } \\
\text { Pedagogia } \\
\text { Pedagogia } \\
\text { Pedagogia } \\
\text { Pedagogia } \\
\text { Pedagogia }\end{array}$ & 2000 a 2009 & $\begin{array}{c}7 \text { anos } \\
9 \text { anos } \\
15 \text { anos } \\
9 \text { anos } \\
5 \text { anos } \\
8 \text { anos } \\
20 \text { anos } \\
8 \text { anos }\end{array}$ \\
\hline 3 & $\begin{array}{c}\text { P8 } \\
\text { P9 } \\
\text { P10 } \\
\text { P14 }\end{array}$ & $\begin{array}{l}\text { Pedagogia } \\
\text { Pedagogia } \\
\text { Pedagogia } \\
\text { Pedagogia }\end{array}$ & 2010 a 2015 & $\begin{array}{l}3 \text { anos } \\
4 \text { anos } \\
3 \text { anos } \\
3 \text { anos }\end{array}$ \\
\hline
\end{tabular}

Fonte: Elaboração própria (2015) 
As respostas variaram principalmente no primeiro grupo de professores, que tiveram suas graduações anteriores ao ano de 1999. Após 1999, houve a expansão da internet nos ambientes escolares e a interconexão mundial adentrou as salas de aulas. Isso pressupôs a preparação dos docentes para esse novo contexto socioeconômico e tecnológico (SILVA, 2004, p. 63).

Para os professores do primeiro grupo, que se formaram entre 1984 a 1999, período em que as abordagens sobre as tecnologias nas escolas ainda eram pouco comuns, o distanciamento entre a tecnologia e o seu uso pedagógico com alunos na escola é visível, pois a tecnologia não fazia parte desse contexto. Esta situação se altera na virada do século XX para o XXI, momento em que os órgãos legisladores demonstram a preocupação com a formação dos indivíduos na sociedade da comunicação e informação. Em decorrência, houve uma expansão da internet nos ambientes escolares e a interconexão mundial adentrou as salas de aula.

Conforme o relato de P13, cuja opinião representa a opinião dos demais professores do grupo, o tema "informática" não era abordado nos cursos de licenciatura em Pedagogia: "Eu terminei a faculdade em 1984, nem se falava nisso. Estava começando a informática" (P13, vinte e sete anos de magistério).

Considerando o contexto socioeconômico e histórico em que se deu a formação desse primeiro grupo de professores, é possível verificar que a preocupação com o uso das TICs ainda não se fazia tão presente. Contudo, esta situação começa a se diferenciar com o Parecer 09/2001, que faz novas orientações para os cursos de licenciatura.

As respostas dos professores que compõem o grupo dois (2000 a 2009), demonstraram outro momento de formação, ou seja, um momento de transição, em que o uso das tecnologias começou a se expandir, mas a preparação para a utilização das TICs nos cursos de graduação, na maioria das vezes, ainda não existia ou não era direcionada para a utilização para fins pedagógicos com os alunos.

Isso pode ser observado no relato do segundo grupo (P3, P6 e P12). Os professores afirmaram que durante a formação inicial tiveram disciplinas que oportunizaram a utilização das TICs, mas com o objetivo de elaboração de slides e de trabalhos acadêmicos. Vejam o que dizem esses professores:

Tinha esse nome mesmo, TICs. Nós não fazíamos muita coisa. O que eu lembro é que nós montamos algumas coisas, algumas apresentações. Não me lembro do tema, mas mexíamos muito no 
computador, e montávamos geralmente apresentações para as disciplinas da faculdade (P3, quinze anos de magistério).

No meu caso, foi mais sobre a metodologia para fazer o Trabalho de Conclusão de Curso, tinha toda a normativa da Associação Brasileira de Normas Técnicas, não estava focada para o uso de tecnologias com os alunos (P6, cinco anos de magistério).

Tive. Era tecnologia da informação. Na época muita gente não sabia usar o computador e acabou virando um cursinho de informática, mas a ideia era que tivesse cunho pedagógico, para trabalhar com as crianças. Eu terminei a faculdade em 2003 (P12, vinte anos de magistério).

Considerando que as TICs começaram a ser utilizadas em sala de aula após o ano de 2002, ou seja, após a implantação do Parecer 09/2001, é compreensível que esses professores tenham recebido formação técnica para elaborar slides, formatar trabalhos, entre outras, uma vez que, conforme mencionado por P12, muitas das alunas dos cursos de licenciaturas ainda não sabiam usar a ferramenta mais característica das TICs, o computador. Para que as TICs possam ser usadas com objetivos pedagógicos, há que se ter conhecimentos técnicos básicos (ANDRADE, 2003), como por exemplo, usar os programas de edição de textos, vídeos e áudios.

No terceiro grupo (período de 2010 - 2015), ocorrem avanços em relação à formação inicial recebida pelos professores entrevistados quanto ao uso das TICs. Conforme relata $\mathrm{P} 10$, no seu curso de licenciatura, o uso das tecnologias para elaboração de trabalhos acadêmicos foi mesclado com questões técnicas para o uso do computador e o uso das TICs para trabalhar com alunos na Educação Básica, Ensino Médio e Educação Infantil:

Sim, tive, tive - As TICs na Educação Básica - foram dois anos dessa disciplina. No primeiro ano foi mais trabalhar com formatação de texto, para fazer o Projeto do TCC, mexer nas ferramentas de Word e Excel, essas coisas. No segundo ano, foi como trabalhar com as tecnologias em sala de aula, como produzir material (P10, três anos de magistério).

No relato acima é possível perceber avanços na formação inicial recebida em relação ao uso das TICs na licenciatura, considerando os dois primeiros grupos de professores. Houve, conforme a fala do docente, a preocupação por parte da instituição de ensino em que se formou em atender os professores que ainda não tinham 
experiências com as ferramentas tecnológicas e, posteriormente, (segundo ano) o uso dessas ferramentas para fins pedagógicos.

Para P8, que além de possuir graduação em Pedagogia, é também graduada em jornalismo, o uso das TICs não causou dificuldades, devido ao fato de ter cursado jornalismo. Em relação a sua primeira formação, afirma: “eu fiz a graduação anterior em jornalismo, então eu já tinha familiaridade com a tecnologia, não necessariamente para fins pedagógicos" (P8, três anos de magistério). Apesar de a primeira graduação não ter como objetivo o uso das TICs para fins pedagógicos e sim para o uso na elaboração de planilhas, edição de textos, gráficos estatísticos, e outros fins relacionados ao curso de Jornalismo, esse primeiro contato com as tecnologias contribuiu para que a professora se familiarizasse com tais ferramentas, conforme pode ser observado no seu relato:

Trabalhar com todas essas ferramentas permitiu que eu perdesse o receio de mexer na máquina, coisa que ocorre com muitos professores que tem medo de estragar o material. Eu sei mexer, não tenho problemas de medo, e isso já é meio caminho andando (P8, três anos de magistério).

Pode-se perceber também, pelo relato da P8, que este contato com as TICs nos dois cursos de graduação contribuiu para a familiarização e a utilização das TICs em sala de aula, proporcionando maior segurança para explorar os recursos tecnológicos existentes na escola. Também se evidencia nessa fala as contribuições dos conhecimentos prévios no ambiente escolar, reforçando que a escola influencia e é influenciada pela sociedade.

Pelas análises das falas dos indivíduos participantes das entrevistas, podemos inferir que as diferentes formações iniciais recebidas foram evoluindo com o passar dos anos. Mas, apesar desses avanços, os professores, ao se depararem com a realidade em sala de aula, ainda percebem que há lacunas na formação inicial em relação às TICs; lacunas que precisam ser preenchidas e que estão relacionadas às tecnologias direcionadas ao uso pedagógico a fim de sintonizar os alunos na sociedade contemporânea, subsidiar esses alunos para se relacionar com a natureza a fim de produzir, reproduzir bens e serviços, informações, conhecimentos e tecnologias.

A formação para o uso das TICs com fins pedagógicos nos cursos de licenciatura muitas vezes não dá conta de atender a velocidade com que ocorre a 
evolução das tecnologias. A falta de base teórica e prática para o uso das TICs com os alunos dificulta o entendimento dos professores de que essas ferramentas também podem e devem ser usadas na sala de aula e outros ambientes para que os alunos possam se beneficiar de suas potencialidades para a aprendizagem. A falta dessa base teórica e prática na formação inicial acaba por distanciar o professor do uso das novas tecnologias, por entenderem que essas ferramentas disponibilizadas na sociedade não podem ser usadas para fins pedagógicos. Vejam a opinião de P13 sobre esta questão: "Não vejo o celular e outras parafernálias tecnológicas como ferramentas pedagógicas. Elas não foram criadas com esse intuito. O objetivo delas é mercadológico e não pedagógico" (P13, vinte e sete anos de magistério).

A formação inicial das professoras do primeiro grupo se deu em outro contexto que não o da sociedade da informação e comunicação. Portanto, na percepção dessa professora (P13), a escola precisa fazer uso apenas de materiais feitos e pensados para a escola, ou seja, a escola isolada dos acontecimentos sociais.

Para atuar na educação de tempo integral, o professor necessita estar receptivo às inovações que se apresentam na sociedade, assim como fazer uso de tais inovações no dia a dia em sala de aula. Para isso, a formação inicial é imprescindível como suporte nas ações pedagógicas que incluem as TICs na aprendizagem dos alunos, tema abordado a seguir.

\section{As Tecnologias da Informação e Comunicação na educação de tempo integral}

As novas tecnologias adentraram o ambiente escolar sem pedir licença aos docentes. Os alunos, partícipes da sociedade da informação e da comunicação, exigem, mesmo que indireta e inconscientemente, o uso de recursos mais modernos.

O anseio por aulas diferenciadas e dinâmicas que por vezes não fazem parte da metodologia de determinados professores, possivelmente induz os alunos, usuários diários de novas tecnologias, a inserir no interior da instituição escolar as mais diferentes mídias, laptops, tablets, aparelhos celulares, objetivando tornar mais atrativo o tempo em que ficam na escola. Segundo os participantes do estudo, a profusão de ferramentas, antes alheias ao ambiente de ensino sistematizado, desestruturou a base da docência acostumada aos livros e cadernos. 
Sem as mínimas condições de reverter o quadro da inovação tecnológica, os professores se viram obrigados a se adequar à nova realidade. Diante desse contexto, foi perguntado aos professores sobre a contribuição das novas tecnologias no processo de ensino-aprendizagem. Todos os respondentes foram unânimes em afirmar que as TICs contribuem para a aprendizagem dos alunos e professores.

Percebendo que os professores responderam intuitivamente sobre as contribuições das TICs, aprofundou-se a questão indagando como percebiam essas contribuições no dia a dia em sala de aula. P14 (três anos no magistério), afirma que, ao usar as TICs em sala de aula, percebe que os alunos ficam mais motivados e participam mais das aulas, questionam e expõem suas opiniões.

Em casa, os alunos que possuem algumas ferramentas que possibilitem a pesquisa na internet, aprofundam os temas trabalhados na escola. A exploração e o aprofundamento desses temas são observados pelos entrevistados como sendo contribuições das TICs. Vejamos o que dizem os professores sobre essa questão:

Oralmente eles comentam, não são todas as crianças; a maioria comenta. Percebo através da oralidade até por ser um primeiro ano. Eles sempre trazem alguma novidade que viram na internet com os pais, comentam sobre assuntos que muitas vezes não estão contempladas no meu planejamento, aí eu preciso adaptar para atender essas crianças que são um pouco mais curiosas (risos) (P2, nove anos no magistério).

Eu percebo que ao fazer algum comentário em sala, no dia seguinte eles trazem mais informações sobre o que eu falei. Quando eu trago alguma coisa diferente eu dou a indicação do site, e eles, em casa, procuram e, anotam na agenda. Ajuda a ampliar o repertório deles. (P12, vinte anos no magistério).

A disponibilização das novas tecnologias em diferentes tempos e espaços facilita o acesso dos alunos aos mais diversos temas, e isso contribui para o enriquecimento das aulas. Na internet, a informação muitas vezes se dá em tempo real, o que exige do professor a relação entre os temas apresentados nos meios de comunicação e o conteúdo previsto no currículo escolar. O aluno, ao aprofundar temas, também proporciona a maleabilidade de um currículo antes engessado. O acesso à internet e ao conteúdo por ela divulgado favorece, na percepção de P2 e P12, a ampliação das discussões sobre temas abordados em aula. 
Além da participação ativa dos alunos, as TICs, no entendimento dos professores, também facilitam a aprendizagem de determinados conteúdos, pois esses são apresentados de forma lúdica, como por exemplo, o uso de jogos didáticos. Os materiais digitais pensados e preparados para uso no ensino-aprendizagem são coloridos e com movimentos, favorecendo a atenção e o interesse das crianças. Nessa perspectiva, os entrevistados consideram que esses materiais, “[...] ajudam o acesso, o brincar, o jogo que você pode mexer no computador. É um jeito diferenciado de a criança ver o conteúdo que você vai trabalhar" (P3, 15 anos no magistério).

Diferentes abordagens metodológicas facilitadas pelas TICs, como mencionado, conseguem atingir um número maior de alunos, já que cada pessoa tem uma maneira distinta de aprender ${ }^{4}$. O uso das TICs contribui para o ensino da Língua Materna, para a produção de textos, e na Matemática auxilia na resolução de problemas e cálculos.

Contudo, o relato de P3 retrata as TICs como artefatos de ilustração de determinado conteúdo. $\mathrm{O}$ fato de trazer algo diferente para a sala de aula não implica necessariamente na aprendizagem do aluno, uma vez que o interesse se deu possivelmente pela ferramenta trazida e não na aprendizagem que se pode oportunizar.

Ao se considerar que os professores entendem que as tecnologias da informação e comunicação contribuem para o processo de ensino-aprendizagem, e, por ser a escola de tempo integral e as TICs objetos de estudo, foi perguntado aos professores se percebem diferenças na aprendizagem dos alunos matriculados no período integral (sete horas ou mais) e dos alunos matriculados no período regular. Entende-se aqui que os alunos que ficam mais horas/dia na escola tenham mais acesso às TICs com direcionamento pedagógico. Vejamos o que alguns professores relatam:

Eu vejo pelas crianças que ficam no integral. Eles têm clube de cinema, os professores utilizam bastante o Datashow e eu percebo que as crianças têm uma melhor desenvoltura para se comunicarem (P2, nove anos no magistério).

Sim, o integral oportuniza mais o uso das TICs pelo tempo de permanência. Muitas crianças não têm computador em casa, então na escola têm acesso, tanto pela manhã quanto no período da tarde. Elas apresentam mais facilidade quando pedimos para pesquisar alguma coisa na internet. São mais críticas. (P7, oito anos no magistério).

${ }^{4}$ Para maior aprofundamento ver: GARDNER, HOWARD. Inteligências Múltiplas: a Teoria na Prática 
Tanto P2 quanto P7 consideram que as crianças que estão matriculadas no tempo integral têm mais acesso às TICs. Porém, o acesso por parte do aluno às TICs se dá passivamente, ou seja, assiste aos filmes no clube de cinema projetados pelo Datashow, que é administrado pelo professor. Já no relato de P7, pode ser percebido certa ação por parte dos alunos, como pesquisas na internet. Nos dois relatos não se consolida a ação criadora por parte do aluno, pois usufruem de algo já pronto.

As aulas do período de contraturno, na percepção docente, são diferenciadas das aulas oferecidas no período regular, e isso também pode ter influência no melhor desempenho dos alunos, já que se trata de aulas/oficinas em que há maior participação dos discentes. Em relação a essa questão os professores relatam que:

A exigência que se trabalhe mais com a prática também contribui. É solicitado que não nos detenhamos ao papel. As salas são diferenciadas. As tecnologias são mais presentes. (P8, três anos no magistério).

O professor tem maior liberdade. Nós podemos trabalhar mais livres sem a cobrança das provas. A relação ensino e aprendizagem se dá de maneira mais livre, mais solta. Os alunos podem criar, inventar e fazer diferente, não necessitam ficar reproduzindo padrões cristalizados da educação. (P9, quatro anos no magistério).

A diferenciação nas aulas do contraturno e no período regular é citada pelos professores como fator a se considerar no aproveitamento acadêmico dos alunos. Não basta ter as TICs disponibilizadas em sala de aula quando não se tem claro o que fazer com elas. $\mathrm{O}$ excesso de burocracia que assola o ensino, principalmente o ensino público, aqui ilustrado no relato de P9 como sendo as provas, contribui negativamente para a aprendizagem, pois a preocupação do professor se divide entre ministrar as aulas, preencher relatórios e aplicar provas.

Contudo, apesar de os professores mencionados anteriormente entenderem que as TICs contribuem para a aprendizagem, principalmente das crianças matriculadas no período integral, há professores que discordam desse posicionamento. Para P5 e P11, o fato de ficar mais horas/dia no ambiente escolar não implica em ter mais acesso às TICs, tampouco diferencia no desenvolvimento e na aprendizagem dessas crianças. Vejamos o que P5 e P11 relataram sobre essa questão: 
Ambos têm acesso. Há laboratórios em praticamente todas as escolas da rede, então, se a tecnologia está disponível as crianças têm acesso. Vai depender do professor, da questão da grade curricular, do que é feito no tempo em que as crianças estão na escola. Tem uma oficina na escola de tempo integral que parece que trabalha com as tecnologias. No regular, se é uma escola que é organizada, tem horários determinados, as crianças também usam o laboratório, e se usam o laboratório, também aprendem como as do período integral. ( $\mathrm{P} 5$, vinte e um anos no magistério).

Tem material nas escolas, às vezes nem sempre em grande quantidade, mas depende do profissional, tem aquele que se dedica tem aquele que não se dedica. Tem aquele que aproveita e que faz uso dos recursos disponíveis na escola e tem aqueles que não; então independe se a criança está no período regular ou integral o professor é o responsável pela aprendizagem (P11, vinte anos no magistério).

Para esses professores, ficar mais horas/dia na escola não implica em mais acesso às TICs e/ou desenvolvimento na aprendizagem, pois, para eles, o professor é quem fará a diferença ou não no aproveitamento escolar das crianças. Se percebe nas falas de P5 e P11 o professor como centro do processo de ensino-aprendizagem. Se bem planejadas as aulas, o aluno que fica apenas quatro horas poderá também ter o acesso às TICs, com aproveitamento acadêmico

O fato de ter laboratório de informática, na percepção de alguns professores, é o suficiente para que haja o aproveitamento das ferramentas disponibilizadas, como se essas fossem autossuficientes. Ao se considerar que apenas o laboratório possa fazer a diferença no processo de ensino-aprendizagem, retira-se das TICs a função social e priorizam-se os materiais (GONÇALVES, 1994).

Diante do exposto, podemos perceber que a formação inicial interfere nas práticas docentes quando se trata da utilização das novas tecnologias no processo de ensino-aprendizagem.

\section{Considerações finais}

Este estudo teve por objetivo identificar qual a contribuição da formação inicial para a efetivação de práticas pedagógicas inovadoras no contexto da escola de tempo integral. 
Pelos relatos dos participantes das entrevistas foi possível perceber que os professores que não tiveram aulas relacionadas ao uso das novas tecnologias na formação inicial, características apresentadas pelo grupo 1 (ver quadro 1), não conseguem perceber as TICs como material a ser usado pedagogicamente nas aulas, e quando muito, percebem nas TICs material para ilustração dos conteúdos trabalhados em sala. Em relação às contribuições das novas tecnologias em sala de aula com as crianças matriculadas em tempo integral e regular, os professores consideram que o acesso às "ferramentas" é o mesmo para os alunos que ficam quatro ou nove horas nas escolas. Para esses professores, o acesso às ferramentas é sinônimo de aprendizagem.

Para os professores do grupo 2, caracterizados como tendo algum tipo de contato com as TICs na formação inicial, foi possível perceber que reproduzem com os alunos a formação recebida, ou seja, utilizam as TICs operacionalmente, e isso inclui a criança jogar no computador, fazer pesquisas na internet, assistir vídeo trazido pelo professor. As TICs servem para ilustração da aula. Diferente do apresentado pelos professores do grupo 1, os professores do grupo 2 percebem que as crianças matriculadas no tempo integral têm mais acesso às TICs pelo tempo que ficam na escola.

Em relação ao grupo 3, foi possível identificar que os professores tiveram, na formação inicial, disciplinas direcionadas aos usos das TICs com cunho pedagógico para uso com os alunos. Esses professores entendem que as TICs contribuem para a produção de novos conhecimentos. Também mencionam sobre a diferença entre as crianças matriculadas no tempo integral e regular. Para eles, as crianças que ficam mais tempo na escola (integral) tem mais acesso às TICs, e, segundo esses professores, tais alunos apresentam-se mais críticos e participativos. O poder de argumentação e o desenvolvimento da oralidade é presente nos alunos do tempo integral.

Corroborando o que Moreira e Kramer (2007) argumentam, os professores entendem que a metodologia utilizada nas oficinas do contraturno, Metodologia de Projetos, oportuniza aulas mais dinâmicas e isso favorece a inserção das TICs naturalmente nas aulas.

Diante disso, podemos compreender então que os professores que tiveram disciplinas relacionadas ao uso das TICs em sala de aula para fins pedagógicos, apresentam-se mais receptivos às inovações em sala de aula. Tais professores conseguem trabalhar com metodologias diferenciadas, proporcionando a participação 
dos alunos como ativos no processo de ensino-aprendizagem, como defendido pelo Parecer 09/2001.

\section{Referências}

ANDRADE, Pedro Ferreira de. Aprender por projetos, formar educadores. (2003). IN. VALENTE, José Armando (Org.). Formação de educadores para o uso da informática na escola. Campinas, UNICAMP/NIED.

BOGDAN, Roberto C. BIKLEN, Sari Knopp. (1994). Investigação qualitativa em educação: uma introdução à teoria e aos métodos. Porto, Portugal: Porto.

BRANDÃO, Edemilson Jorge Ramos. CAMPOS, Aline de. FRANCO, Sergio Roberto Kieling. TEIXEIRA, Adriano Canabarro. (2004). Imersão tecnológica de professores: uma alternativa de reversão de quadros de exclusão sociotecnológica. Revista Diálogo Educacional, Curitiba, v. 4, n.13, p.101-112, set./dez. Disponível em <www2.pucpr.br/reol/index.php/dialogo?dd99=pdf\&dd1=764>. Acesso em: $29 \mathrm{dez}$. 2015.

BRASIL, Ministério da Educação. Secretaria de Educação Básica. Diretoria de Currículos e Educação Integral. (2013). Manual operacional de educação integral. Brasília. Disponível em $<$ http://portal.mec.gov.br/index.php?option=com_docman\&view $=$ download\&alias $=144$ 58-manual-mais-educacao-2013-final-171013-2-pdf\&category_slug=outubro-2013pdf\&Itemid=30192>. Acesso em: 15 fev.2015.

BRASIL, INSTITUTO NACIONAL DE ESTUDOS E PESQUISAS EDUCACIONAIS ANÍSIO TEIXEIRA. (2014). Censo Escolar da Educação Básica 2013: resumo técnico / Instituto Nacional de Estudos e Pesquisas

Educacionais Anísio Teixeira. - Brasília: O Instituto. Disponível em

$<$ http://download.inep.gov.br/educacao_basica/censo_escolar/resumos_tecnicos/resumo _tecnico_censo_educacao_basica_2013.pdf.>. Acesso em: 10 jul. 2014.

BRASIL, Ministério da Educação. Conselho Nacional de Educação. (2001). Parecer CNE 09/2001. Publicado no Diário Oficial da União em 18/01/2002, Seção 1, p. 31. Disponível em:< http://portal.mec.gov.br/cne/arquivos/pdf/009.pdf $>$. Acesso: 21 jul 2015.

BRASIL, Secretaria de Educação Fundamental. (1997) Parâmetros curriculares nacionais: introdução aos parâmetros curriculares nacionais / Secretaria de Educação Fundamental. - Brasília: MEC/SE. Disponível em: <http://portal.mec.gov.br/seb/arquivos/pdf/livro01.pdf>. Acesso: 20 mar.2015.

ETEOKLEOUS, Nikleia. Evaluating computer technology integration in a centralized school system. (2007) Computer \& Education. Disponível em: <www.elsevier.com/locate/compedu>. Acesso: 18 jun. 2014. 
FANTIN, Monica. Mídia-Educação no currículo e na formação inicial de professores.(2012) In. FANTIN, Monica. RIVOLTELLA, Pier Cesare (orgs). Cultura e digital e escola: pesquisa e formação de professores. Campinas: SP. Papirus.

FLICK, Uwe. (2009). Desenho da pesquisa qualitativa. Porto Alegre: Artmed.

GADOTTI, Moacir. (2009). Educação integral no Brasil: inovações em processo. São Paulo: Instituto Paulo Freire, 2009.

FREIRE FILHO, João. LEMOS, João Francisco de. (2008). Imperativos de conduta juvenil no século XXI: a "Geração Digital” na mídia impressa brasileira. Comunicação, mídia e consumo. São Paulo vol.5 n.13 p.11-25 jul.2008. Disponível em: <http://revistacmc.espm.br/index.php/revistacmc/article/view/124>. Acesso: 10 set.2014.

GONÇALVES, José Ernesto Lima. (1994). Os impactos das novas tecnologias nas empresas prestadoras de serviços. Revista de Administração de Empresas. São Paulo, jan. /fev. Disponível em <http://www.scielo.br/pdf/rae/v34n1/a08v34n1>. Acesso em: 01 ago. 2015.

KARSENTI, Thierry. VILLENEUVE, Stéphane. RABY, Carole. (2008). O uso pedagógico das tecnologias da informação e da comunicação na formação dos futuros docentes no Quebec. Educação e Sociedade. Campinas, vol. 29, nº 104 - Especial p. 865-889, out. Disponível em <http://www.cedes.unicamp.br>. Acesso em: 26 fev. 2014.

MOLL, Jaqueline. (2011). Educação integral no Brasil: itinerários na construção de uma política pública possível. IN. Vários autores. Tendências para a educação integral. São Paulo. Fundação Itaú Social, CENPEC. Disponível em: <http://www.fundacaoitausocial.org.br/_arquivosestaticos/FIS/pdf/ed_integral.pdf_ $>$. Acesso em: 17 jul. 2013.

MOREIRA, Antônio Flávio Barbosa. KRAMER, Sonia. (2007). Contemporaneidade, educação e tecnologia. Educação e Sociedade. Campinas, vol. 28, n 100 - Especial 1037-1057, out. Disponível em <http://www.cedes.unicamp.br>. Acesso em: 23 mar. 2015 .

NÓVOA, António. (2001). Pela Educação. Entrevista concedida em nov.2001 para VIEIRA, Maria Cristina. PEREIRA, Henrique Manuel S. Saber e Educar 11/2006 p. 111-126. Disponível em: < http://koha.ulusiada.pt/cgi-bin/koha/opacdetail.pl?biblionumber=182422>. Acesso: 15 dez. 2014.

RIVOLTELLA, Pier Cesare. (2012). Retrospectivas e tendências da pesquisa em mídia-educação no contexto internacional. In: RIVOLTELLA, Pier Cesare. FANTIN, Monica. Cultura digital e escola: pesquisa e formação de professores. Campinas. Papirus.

SILVA, Marco. Internet na escola e inclusão. (2004). IN. Tecnologias na escola (coletânea de artigos). Ministério da Educação, Brasília. Disponível em: <http://portal.mec.gov.br/seed/arquivos/pdf/2sf.pdf>. Acesso: 11 ago.2015. 
TAKAHASHI, Tadao (org). (2000). Sociedade da informação no Brasil: livro verde. Ministério da Ciência e Tecnologia. Brasília. Disponível em: <http://livroaberto.ibict.br/bitstream/1/434/1/Livro\%20Verde.pdf.> Acesso em: 26 jun. 2014.

UNESCO. O perfil dos professores brasileiros: o que fazem o que pensam o que almejam. (2004) Pesquisa Nacional UNESCO. São Paulo: Moderna. Disponível em http://unesdoc.unesco.org/images/0013/001349/134925por.pdf. Acesso: 24 mai.2014.

\section{Como referenciar este artigo}

ROCHA, Rozane de Fátima Zaionz da.; MOREIRA, Herivelto. Escolas públicas do município de Curitiba: as novas tecnologias nas escolas de tempo integral. Revista Ibero-Americana de Estudos em Educação, Araraquara, v.12, n.1, p. 350-370, 2017. Disponível em: 〈http://dx.doi.org/10.21723/riaee.v12.n1.8476>. E-ISSN: 1982-5587.

Data de submissão: $\operatorname{mar} / 2016$

Aprovação final: jan/2017 